\title{
Vitamin C Improves Endothelium-dependent Vasodilation in Patients with Non-Insulin-dependent Diabetes Mellitus
}

\author{
Henry H. Ting, Farris K. Timimi, Kimberly S. Boles, Shelly J. Creager, Peter Ganz, and Mark A. Creager \\ Vascular Medicine and Atherosclerosis Unit, Cardiovascular Division, Brigham and Women's Hospital and Harvard Medical School, \\ Boston, Massachusetts 02115
}

\begin{abstract}
Endothelium-dependent vasodilation is impaired in humans with diabetes mellitus. Inactivation of endotheliumderived nitric oxide by oxygen-derived free radicals contributes to abnormal vascular reactivity in experimental models of diabetes. To determine whether this observation is relevant to humans, we tested the hypothesis that the antioxidant, vitamin $\mathrm{C}$, could improve endothelium-dependent vasodilation in forearm resistance vessels of patients with non-insulin-dependent diabetes mellitus. We studied 10 diabetic subjects and 10 age-matched, nondiabetic control subjects. Forearm blood flow was determined by venous occlusion plethysmography. Endothelium-dependent vasodilation was assessed by intraarterial infusion of methacholine (0.3-10 $\mu \mathrm{g} / \mathrm{min})$. Endothelium-independent vasodilation was measured by intraarterial infusion of nitroprusside (0.3-10 $\mu \mathrm{g} / \mathrm{min})$ and verapamil (10-300 $\mu \mathrm{g} / \mathrm{min})$. Forearm blood flow dose-response curves were determined for each drug before and during concomitant intraarterial administration of vitamin C ( $24 \mathrm{mg} / \mathrm{min})$. In diabetic subjects, endothelium-dependent vasodilation to methacholine was augmented by simultaneous infusion of vitamin $C(P=0.002)$; in contrast, endothelium-independent vasodilation to nitroprusside and to verapamil were not affected by concomitant infusion of vitamin $C(P=0.9$ and $P=0.4$, respectively). In nondiabetic subjects, vitamin $\mathrm{C}$ administration did not alter endothelium-dependent vasodilation $(P=0.8)$. We conclude that endothelial dysfunction in forearm resistance vessels of patients with non-insulin-dependent diabetes mellitus can be improved by administration of the antioxidant, vitamin $\mathrm{C}$. These findings support the hypothesis that nitric oxide inactivation by oxygen-derived free radicals contributes to abnormal vascular reactivity in diabetes. $(J$. Clin. Invest. 1996. 97:22-28.) Key words: ascorbate • antioxidants • free radicals • endothelium-derived relaxing factor • vascular
\end{abstract}

Address correspondence to Mark A. Creager, Cardiovascular Division, Brigham and Women's Hospital, 75 Francis Street, Boston, MA 02115. Phone: 617-732-5267; FAX: 617-232-2749.

Received for publication 11 July 1995 and accepted in revised form 21 September 1995.

1. Abbreviation used in this paper: AGE, advanced glycosylation end products.

J. Clin. Invest.

(c) The American Society for Clinical Investigation

0021-9738/96/01/0022/07 \$2.00

Volume 97, Number 1, January 1996, 22-28

\section{Introduction}

Diabetes mellitus is a disease with protean manifestations, the most devastating being its vascular complications. Atherosclerosis, involving cardiac, cerebral, and peripheral vasculature, develops earlier in diabetic than nondiabetic subjects and accounts for the largest fraction of excess morbidity and mortality (1-3). Diabetes mellitus is also associated with premature microvascular disease which contributes importantly to complications such as retinopathy and nephropathy $(4,5)$.

The endothelium plays an important role in maintaining vascular tone and function, in part by the synthesis and release of vasoactive substances such as nitric oxide (6-9). Abnormalities in endothelial function may contribute to the pathogenesis of vascular disease in diabetics and can be detected before the development of overt atherosclerosis. Impaired endotheliumdependent vasomotion has been reported in patients with insulin-dependent (type I) and non-insulin-dependent (type II) diabetes mellitus (10-15). The mechanism of endothelial dysfunction in diabetes mellitus is not known, but one possibility is increased inactivation of endothelium-derived nitric oxide by oxygen-derived free radicals. In animal models of diabetes, endothelium-dependent relaxation can be completely restored by treatment with antioxidants (16-20).

The primary objective of this study was to determine whether observations made in animal models of diabetes could be extended to humans. Vitamin $\mathrm{C}$ is an important antioxidant in human plasma, capable of scavenging oxygen-derived free radicals and sparing other endogenous antioxidants from consumption (21-24). Plasma and tissue levels of vitamin $\mathrm{C}$ are $40-50 \%$ lower in diabetic compared with nondiabetic subjects (25-27). Accordingly, we sought to test the hypothesis that the antioxidant, vitamin C, can improve endothelium-dependent vasodilation in patients with non-insulin-dependent diabetes mellitus.

\section{Methods}

Subjects. The study population included 10 patients with non-insulin-dependent diabetes mellitus, defined according to the National Diabetes Data Group criteria (28), and 10 nondiabetic control subjects. The patients with non-insulin-dependent diabetes mellitus (six men and four women) had an average age of $47 \mathrm{yr}$ (35-55 yr). The duration of diabetes averaged $39 \pm 8$ mo (10-84 mo). Diabetic subjects received treatment with diet alone $(n=2)$, diet plus oral sulfonylurea $(n=6)$, or diet plus insulin injections $(n=2)$. The nondiabetic subjects (five men and five women) had an average age of 44 yr (36-51 yr). All subjects were recruited from the Boston area via advertisements in local newspapers. Each subject was screened by a complete history, physical examination, and laboratory analysis. Exclusion criteria for both diabetic and nondiabetic subjects included any of the following: hypertension (defined as blood pressure $>140 / 90$ ), tobacco use within the past $5 \mathrm{yr}$, hypercholesterolemia (defined as LDL > 75th percentile for age and sex), use of antioxidant vitamin supple- 
ments or hormone replacement therapy, clinical evidence of cardiac or pulmonary disease, laboratory evidence of renal, hepatic, or hematologic abnormalities, and current use of antihypertensive, cardiac, or other vasoactive medications. No diabetic or nondiabetic subject had clinical evidence of atherosclerosis, as documented by the absence of symptoms such as angina, claudication, or cerebrovascular ischemia, and the absence of physical findings including diminished pulses, asymmetric blood pressure, or bruits. This study was approved by the Human Research Committee of Brigham and Women's Hospital and each subject gave written informed consent.

Drug infusion protocol. Methacholine chloride (Roche Laboratories, Division of Hoffman-La Roche Inc., Nutley, NJ), a congener of acetylcholine, was administered via the brachial artery to assess vasodilation resulting from endothelium-derived nitric oxide. Forearm blood flow was measured during infusion of increasing concentrations of methacholine at doses of $0.3,1.0,3.0$, and $10.0 \mu \mathrm{g} / \mathrm{min}$.

Sodium nitroprusside (Elkins-Sinn Inc., Cherry Hill, NJ) was administered via the brachial artery to assess the vasodilator response to an exogenous nitric oxide donor. Forearm blood flow was determined during infusion of increasing concentrations of nitroprusside at doses of $0.3,1.0,3.0$, and $10.0 \mu \mathrm{g} / \mathrm{min}$.

Verapamil (American Reagent Laboratory Inc., Shirley, NY), a calcium channel blocker, was administered via the brachial artery to assess vascular smooth muscle relaxation not dependent on endothelium-derived or exogenous nitric oxide. Forearm blood flow was measured during infusion of increasing concentrations of verapamil at doses of $10,30,100$, and $300 \mu \mathrm{g} / \mathrm{min}$.

Vitamin C (sodium ascorbate; Abbott Laboratories, Chicago, IL) was administered via the brachial artery to assess whether this antioxidant vitamin modified the vasodilator responses to methacholine, nitroprusside, or verapamil. Vitamin $\mathrm{C}$ was infused at a constant dose of $24 \mathrm{mg} / \mathrm{min}$ and rate of $0.4 \mathrm{ml} / \mathrm{min}$ to limit the total vitamin $\mathrm{C}$ dose to $<1,000 \mathrm{mg}$ and to approximate a local forearm concentration of 1-10 $\mathrm{mM}$. This vitamin C concentration in vitro completely protected human plasma from free radical-mediated lipid peroxidation (23).

The doses of each drug were chosen to achieve a significant change in forearm blood flow and forearm vascular resistance without causing systemic effects. Hemodynamic measurements were performed after infusion of methacholine, nitroprusside, or verapamil for $3 \mathrm{~min}$ at each dose, administered at $0.4 \mathrm{ml} / \mathrm{min}$.

Experimental protocol. Each subject was studied in the vascular research laboratory in the postabsorptive state. The room was quiet, lights were dimmed, and temperature was controlled at $23^{\circ} \mathrm{C}$. Alcohol, caffeine, and all medications including sulfonylurea and insulin were withheld within $12 \mathrm{~h}$ of the study. Aspirin and nonsteroidal antiinflammatory medications were withheld within $7 \mathrm{~d}$ of the study. Under local anesthesia and sterile conditions, a 20-gauge polyethylene catheter was inserted into a brachial artery of each subject for determination of blood pressure and infusion of drugs. All subjects rested for at least $30 \mathrm{~min}$ after catheter placement to achieve a stable baseline before data collection.

At the beginning of each protocol, normal saline $(0.9 \%$ sodium chloride) was infused intraarterially at a rate of $0.4 \mathrm{ml} / \mathrm{min}$, and baseline measurements of forearm blood flow and blood pressure were obtained every $10 \mathrm{~min}$ until stable. Each diabetic and nondiabetic subject underwent the following experimental protocol: $(a)$ an initial forearm blood flow dose-response curve to methacholine; $(b)$ a rest period of at least $60 \mathrm{~min}$ to reestablish stable forearm blood flow comparable to baseline measurements; $(c)$ administration of vitamin $\mathrm{C}$ intraarterially for $10 \mathrm{~min}$, followed by measurement of forearm blood flow; and $(d)$ a second forearm blood flow dose-response curve to concomitant infusion of methacholine and vitamin C. Using a similar design, eight diabetic subjects also participated in two additional protocols on separate dates to assess forearm blood flow doseresponse curves to nitroprusside and verapamil, before and after concomitant infusion of vitamin $\mathrm{C}$.

Hemodynamic measurements. Bilateral forearm blood flow was determined by venous occlusion strain gauge plethysmography, using calibrated mercury-in-silastic strain gauges, and expressed as milliliters per 100 milliliters of tissue per min (D. E. Hokanson, Issaquah, WA). Each arm was supported above the heart level. Venous occlusion pressure averaged $35 \pm 1 \mathrm{mmHg}$. Circulation to the hand was prevented by inflating a wrist cuff to suprasystolic pressures before each forearm blood flow determination. Each forearm blood flow determination comprised at least five separate measurements at $10-15 \mathrm{~s}$ intervals. The vascular response to each drug was determined by measuring the forearm blood flow in the drug infusion arm, and potential systemic effects of each drug dose were assessed by measuring the forearm blood flow in the contralateral arm. Forearm vascular resistance was calculated as the ratio of mean blood pressure to forearm blood flow and expressed as units reflecting $\mathrm{mmHg}$ per milliliter per 100 milliliters of tissue per min.

Blood pressure was measured via the arterial cannula which was attached to a pressure transducer (P23; Statham Instruments, Hato Rey, PR) aligned to an amplifier on a physiologic recorder (Gould Inc., Cleveland, $\mathrm{OH})$. Heart rate was determined from a simultaneously obtained electrocardiographic signal and calculated from the RR interval.

Statistical analysis. All measurements are presented as mean \pm standard error. Analyses of the difference in clinical characteristics between diabetic and nondiabetic subjects were made using unpaired and two-tailed $t$ tests. Statistical analyses of the dose-response curves for each drug before and during concomitant infusion of vitamin $\mathrm{C}$ used two-way ANOVA for repeated measures. Comparisons of the vasodilator responses before and during concomitant infusion of vita$\min \mathrm{C}$ for each drug dose were made using two-tailed $t$ tests, unpaired or paired as appropriate, and adjusted with a Bonferonni correction for multiple comparisons. Statistical significance was accepted at the 95\% confidence level $(P<0.05)$.

\section{Results}

The clinical characteristics of the study population are provided in Table I. The diabetic and nondiabetic subjects were matched for age. No subject had evidence of hypertension, hypercholesterolemia, tobacco use, or cardiovascular disease. The mean blood pressure, total cholesterol, HDL, LDL, blood urea nitrogen, and creatinine were similar in both groups. Diabetic subjects had significantly higher glucose, glycosylated hemoglobin, insulin, and triglyceride levels.

Basal forearm blood flow and vitamin $C$. The baseline forearm blood flow was comparable between diabetic and

\section{Table I. Clinical Characteristics of Study Population}

\begin{tabular}{lcc}
\hline & Diabetic subjects & Nondiabetic subjects \\
\hline Number & 10 & 10 \\
Age (yr) & $47 \pm 2$ & $44 \pm 2$ \\
Sex (male/female) & $6 / 4$ & $5 / 5$ \\
Mean blood pressure (mmHg) & $75 \pm 3$ & $81 \pm 4$ \\
Total cholesterol (mg/dl) & $194 \pm 10$ & $178 \pm 8$ \\
HDL (mg/dl) & $32 \pm 3$ & $40 \pm 2$ \\
LDL (mg/dl) & $121 \pm 8$ & $117 \pm 7$ \\
Triglycerides (mg/dl) & $302 \pm 70$ & $106 \pm 13^{*}$ \\
Glucose (mg/dl) & $197 \pm 30$ & $79 \pm 3^{\ddagger}$ \\
Blood urea nitrogen (mg/dl) & $15 \pm 1$ & $16 \pm 1$ \\
Creatinine (mg/dl) & $1 \pm 0.1$ & $1 \pm 0.1$ \\
Glycosylated hemoglobin $(\%)$ & $7.9 \pm 0.7$ & $4.4 \pm 0.1^{\ddagger}$ \\
Insulin $(\mu \mathrm{U} / \mathrm{ml})$ & $21 \pm 7$ & $5 \pm 1^{*}$ \\
& &
\end{tabular}

Data presented as mean \pm standard error. ${ }^{*} P<0.05,{ }^{*} P<0.01 \mathrm{com}-$ pared with diabetic subjects. 
nondiabetic subjects, $2.4 \pm 0.3$ and $2.1 \pm 0.3 \mathrm{ml} / 100 \mathrm{ml}$ tissue per min, respectively $(P=\mathrm{NS})$. The baseline forearm vascular resistance was $37 \pm 5.4 \mathrm{U}$ in diabetic subjects and $43 \pm 5.7 \mathrm{U}$ in nondiabetic subjects $(P=\mathrm{NS})$. Intraarterial administration of vitamin $\mathrm{C}$ at $24 \mathrm{mg} / \mathrm{min}$ did not change baseline forearm blood flow in diabetic subjects, $2.4 \pm 0.3-2.9 \pm 0.3 \mathrm{ml} / 100 \mathrm{ml}$ tissue per $\min (P=\mathrm{NS})$ or nondiabetic subjects, $2.1 \pm 0.3-2.2 \pm 0.2 \mathrm{ml} / 100$ $\mathrm{ml}$ tissue per $\min (P=\mathrm{NS})$.

Vasodilator response to methacholine and vitamin $C$. Methacholine infusion increased forearm blood flow in both diabetic and nondiabetic subjects (Fig. 1). However, the vasodilator response to methacholine was significantly attenuated in diabetic subjects compared with nondiabetic subjects $(P=$ 0.01 by ANOVA). At the highest dose of methacholine $(10 \mu \mathrm{g} /$ $\mathrm{min}$ ), the forearm blood flow increased to $12.5 \pm 1.6 \mathrm{ml} / 100 \mathrm{ml}$ tissue per min in diabetic subjects compared to $19.8 \pm 1.9$ $\mathrm{ml} / 100 \mathrm{ml}$ tissue per min in nondiabetic subjects $(P<0.05)$. At this dose, there was a trend for a higher forearm vascular resistance in diabetic subjects, $7.8 \pm 1.8 \mathrm{U}$, compared with nondiabetic subjects, $4.4 \pm 0.6 \mathrm{U}(P=0.09)$.

In patients with non-insulin-dependent diabetes mellitus, the vasodilator dose-response curve to methacholine was significantly augmented by simultaneous infusion of methacholine and vitamin $\mathrm{C}$ (Fig. $2, P=0.002$ by ANOVA). At the maximal dose of methacholine $(10 \mu \mathrm{g} / \mathrm{min})$, the forearm blood flow increased from $12.5 \pm 1.6$ to $17.0 \pm 1.9 \mathrm{ml} / 100 \mathrm{ml}$ tissue per min during concomitant infusion of vitamin $\mathrm{C}(P<0.05)$. At this dose, the forearm vascular resistance decreased from $7.8 \pm 1.8$ to $5.5 \pm 1.3 \mathrm{U}$ during infusion of vitamin $\mathrm{C}(P<0.05)$.

In contrast, the vasodilator dose-response curve to methacholine in nondiabetic control subjects was not altered by simultaneous infusion of methacholine and vitamin $\mathrm{C}$ (Fig. 3, $P=0.8$ by ANOVA). At the maximal dose of methacholine $(10 \mu \mathrm{g} / \mathrm{min})$, the forearm blood flow was similar before and during concomitant infusion of vitamin C, 19.8 \pm 1.9 and

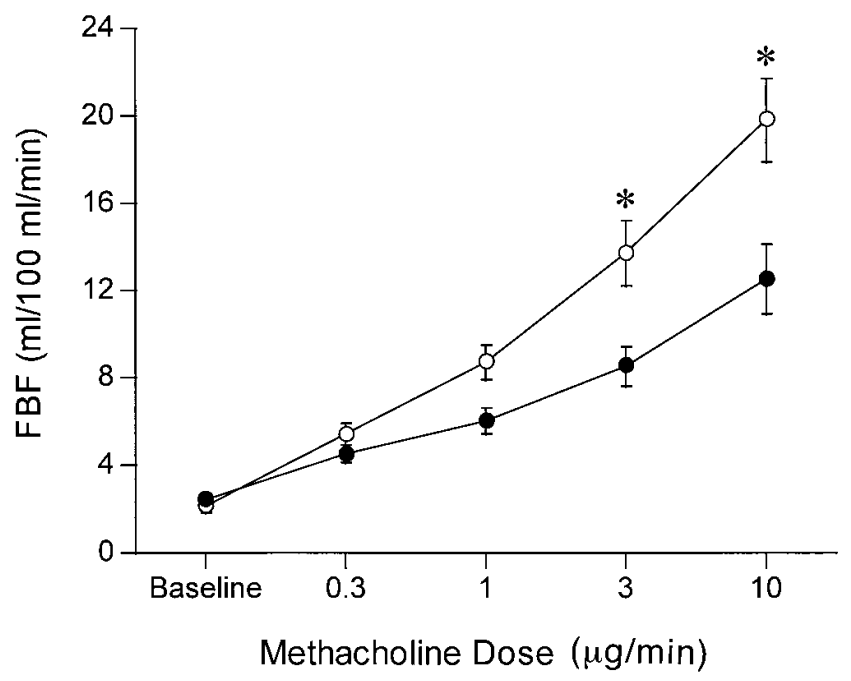

Figure 1. Forearm blood flow $(F B F)$ dose-response curves to methacholine in diabetic $(\bullet)$ and nondiabetic $(O)$ subjects. The endothelium-dependent vasodilation to methacholine was significantly attenuated in diabetic subjects compared with nondiabetic subjects $(P=$ 0.01 by ANOVA). Comparisons of forearm blood flow at each methacholine dose between diabetic and nondiabetic subjects were perfomed by unpaired $t$ tests adjusted with a Bonferonni correction for multiple comparisons. $* P<0.05$.

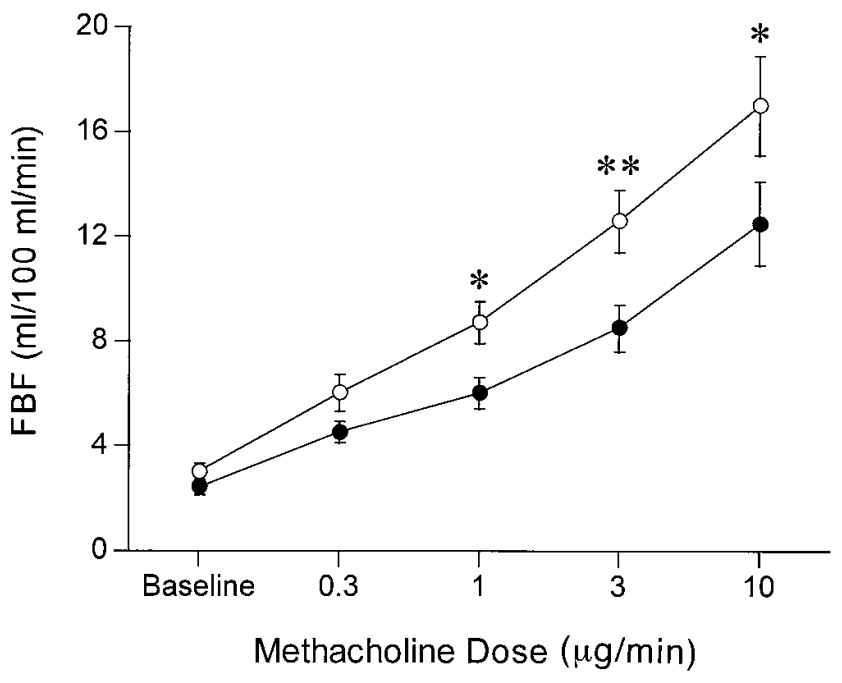

Figure 2. Forearm blood flow $(F B F)$ dose-response curves to methacholine $(\bullet)$ and methacholine plus vitamin $\mathrm{C}(\bigcirc)$ in diabetic subjects. The endothelium-dependent vasodilation to methacholine was augmented during concomitant infusion of methacholine and vitamin $\mathrm{C}$ ( $P=0.002$ by ANOVA). Comparisons of forearm blood flow at each methacholine dose before and during vitamin $\mathrm{C}$ administration were performed by paired $t$ tests adjusted with a Bonferonni correction for multiple comparisons. $* P<0.05 ; * * P<0.01$.

$20.6 \pm 2.0 \mathrm{ml} / 100 \mathrm{ml}$ tissue per min, respectively $(P=\mathrm{NS})$. At this dose, the forearm vascular resistance was not changed before and during infusion of vitamin $\mathrm{C}, 4.4 \pm 0.6$ and $4.3 \pm 0.5 \mathrm{U}$, respectively $(P=\mathrm{NS})$.

Methacholine administration did not affect forearm blood flow or forearm vascular resistance in the contralateral arm and did not alter systemic blood pressure or heart rate in either group.

Vasodilator response to nitroprusside and vitamin $C$. In patients with non-insulin-dependent diabetes, the forearm blood flow dose-response curve to nitroprusside was not altered by

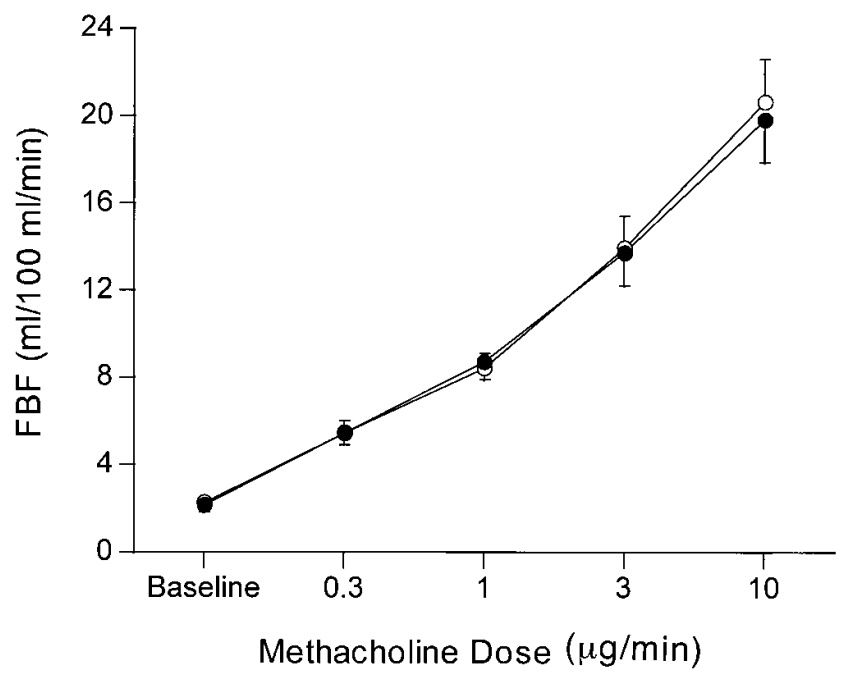

Figure 3. Forearm blood flow $(F B F)$ dose-response curves to methacholine $(\bullet)$ and methacholine plus vitamin $\mathrm{C}(O)$ in nondiabetic subjects. The endothelium-dependent vasodilation to methacholine was not altered during concomitant infusion of methacholine and vitamin $\mathrm{C}(P=0.8$ by ANOVA $)$. 


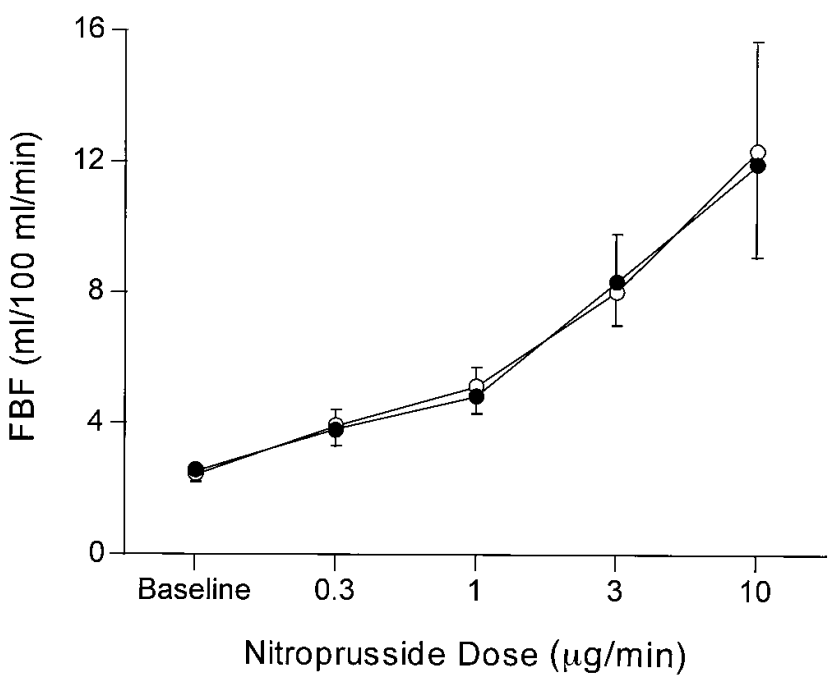

Figure 4. Forearm blood flow $(F B F)$ dose-response curves to nitroprusside $(\bullet)$ and nitroprusside plus vitamin $\mathrm{C}(O)$ in diabetic subjects. The endothelium-independent vasodilation to nitroprusside was not altered during concomitant infusion of nitroprusside and vitamin C. $P=0.9$ by ANOVA.

simultaneous infusion of nitroprusside and vitamin $\mathrm{C}$ (Fig. 4, $P=0.9$ by ANOVA). At the maximal dose of nitroprusside $(10 \mu \mathrm{g} / \mathrm{min})$, the forearm blood flow was $11.9 \pm 2.8$ before and $12.3 \pm 3.4 \mathrm{ml} / 100 \mathrm{ml}$ tissue per min during concomitant infusion of vitamin $\mathrm{C}(P=\mathrm{NS})$. At this dose, the forearm vascular resistance remained similar before and during infusion of vitamin C, $8.7 \pm 1.4$ and $11.7 \pm 4.1 \mathrm{U}$, respectively $(P=\mathrm{NS})$. Nitroprusside infusion did not change forearm blood flow or forearm vascular resistance in the contralateral arm and did not significantly affect systemic blood pressure or heart rate.

Vasodilator response to verapamil and vitamin $C$. Analogous to the vasodilator response observed with nitroprusside, the forearm blood flow dose-response curves to verapamil alone and verapamil plus vitamin $\mathrm{C}$ were not different in pa-

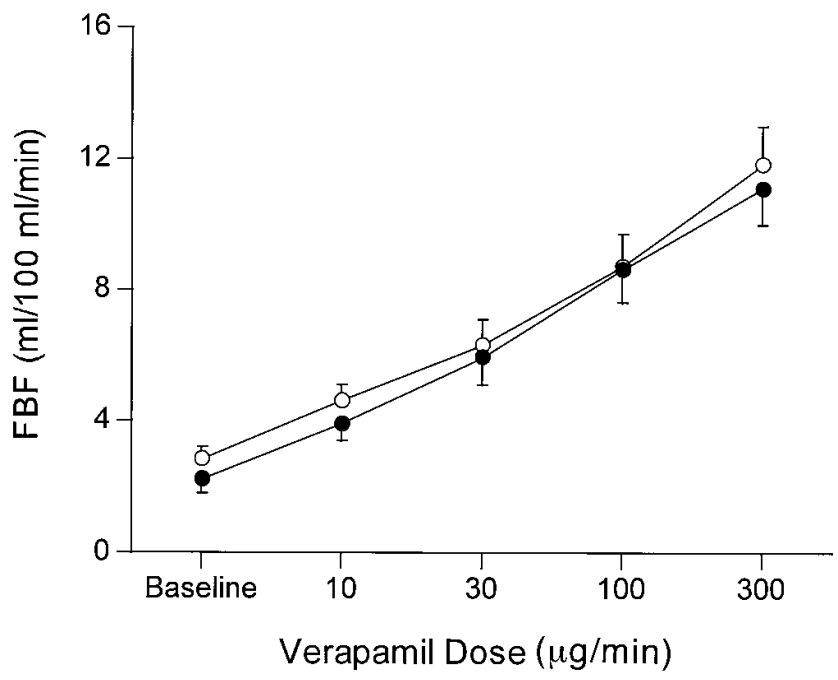

Figure 5. Forearm blood flow $(F B F)$ dose-response curves to verapamil (๑) and verapamil plus vitamin $\mathrm{C}(\bigcirc)$ in diabetic subjects. The endothelium-independent vasodilation to verapamil was not altered during concomitant infusion of verapamil and vitamin C. $P=0.4$ by ANOVA. tients with non-insulin-dependent diabetes (Fig. $5, P=0.4$ by ANOVA). At the maximal dose of verapamil $(300 \mu \mathrm{g} / \mathrm{min})$, the forearm blood flow was comparable before and during concomitant infusion of vitamin $\mathrm{C}, 11.1 \pm 1.1$ and $11.8 \pm 1.2 \mathrm{ml} /$ $100 \mathrm{ml}$ tissue per min, respectively $(P=\mathrm{NS})$. At this dose, the forearm vascular resistance was not altered by infusion of vitamin C, $8.3 \pm 1.3$ and $8.1 \pm 1.4 \mathrm{U}$, respectively $(P=\mathrm{NS})$. Forearm blood flow and forearm vascular resistance did not change in the contralateral arm during infusion of verapamil. Blood pressure and heart rate also remained stable during verapamil administration.

\section{Discussion}

Vascular function in diabetes mellitus has been studied extensively in both animal models and humans. Impaired endothelium-dependent vasodilation has been a consistent finding in animal models of diabetes induced by alloxan or streptozotocin (29-36). Arteries isolated from normal animals which are subsequently exposed to exogenous hyperglycemia also exhibited attenuated endothelium-dependent relaxation $(17,37)$. Similarly, studies in humans with insulin-dependent and noninsulin-dependent diabetes mellitus have found endothelial dysfunction when compared to vascular function in nondiabetic subjects (10-15). Our study confirms previous observations that endothelium-dependent vasodilation is impaired in patients with non-insulin-dependent diabetes mellitus. The important new finding is that endothelial dysfunction in forearm resistance vessels of patients with non-insulin-dependent diabetes mellitus can be significantly improved by acute administration of the antioxidant, vitamin C. In contrast, vitamin $\mathrm{C}$ does not augment endothelium-dependent vasodilation in nondiabetic control subjects.

The endothelium is an important modulator of vascular tone and function through the synthesis and release of endothelium-derived nitric oxide (6-9). The forearm vascular response to methacholine chloride depends on the health and integrity of the endothelium and the endothelium-derived nitric oxide pathway. The mechanisms responsible for endothelial dysfunction in patients with diabetes mellitus are not completely understood. Among the possibilities are: decreased synthesis or release of nitric oxide by endothelial cells; decreased responsiveness of vascular smooth muscle to endothelium-derived nitric oxide; and increased inactivation of endothelium-derived nitric oxide by oxygen-derived free radicals.

Nitric oxide is inactivated by oxygen-derived free radicals, particularly superoxide anion (38-41). Increased vascular production of superoxide anion contributes importantly to impaired endothelium-dependent vascular relaxation in animal models of hypercholesterolemia (42-45). Studies in animal models of diabetes also support nitric oxide inactivation by oxygen-derived free radicals as a cause of endothelial dysfunction (16-20). In isolated aortic rings from normal rabbits exposed to hyperglycemia, Tesfamariam and Cohen (16) found that the attenuated endothelium-dependent relaxation can be prevented by treatment with SOD (a scavenger of superoxide anion) or catalase (a scavenger of hydrogen peroxide). Bohlen and Lash (17) extended these findings and found that mesenteric arterioles from normal rats exposed to hyperglycemia exhibited endothelial dysfunction which can also be prevented by treatment with SOD or catalase. Similarly, in the mesenteric arterioles from streptozotocin-induced diabetic rats, 
Diederich and colleagues (18) showed that SOD or 1,3-dimethyl-2-thiourea (a scavenger of hydroxyl radicals) completely restored the impaired endothelium-dependent relaxation to the level of vasodilation observed in nondiabetic rats. In analogous experiments in the aorta from diabetic rats, other investigators have also reported that the impaired endotheliumdependent relaxation can be normalized after treatment with $\operatorname{SOD}(19,20)$.

The present study extends observations made in these experimental models of diabetes to patients with non-insulin-dependent diabetes mellitus. Acute administration of the antioxidant, vitamin $\mathrm{C}$, significantly improved endothelium-dependent vasodilation to methacholine, whereas the endothelium-independent vasodilator response to nitroprusside, an exogenous nitric oxide donor, and to verapamil, a direct smooth muscle relaxant, were not significantly altered by administration of vitamin C.

The improvement in endothelium-dependent vasodilation in diabetic subjects is probably mediated by the ability of vitamin $\mathrm{C}$ to scavenge excess superoxide anions and, thereby, decrease nitric oxide inactivation. In vitro experiments have demonstrated that vitamin $\mathrm{C}$ has the capacity to scavenge superoxide anion (46-49). The reaction rate constants are estimated to be $3 \times 10^{5} \mathrm{M}^{-1} \mathrm{~s}^{-1}$ between vitamin $\mathrm{C}$ and superoxide anion $(46,48,49)$ and $2 \times 10^{9} \mathrm{M}^{-1} \mathrm{~s}^{-1}$ between SOD and superoxide anion $(47,49,50)$. Despite a $10^{4}$ slower reaction rate observed with vitamin $\mathrm{C}$, tissue vitamin $\mathrm{C}$ concentrations are $10^{4}$ greater than that of SOD $(46,47,51)$, enabling vitamin C to competitively scavenge superoxide anion. However, we cannot rule out the possibility that vitamin $\mathrm{C}$ binds and stabilizes endothelium-derived nitric oxide, increasing the availability of endothelium-derived nitric oxide by a mechanism independent of free radical scavenging.

There are a number of potential sources of oxygen-derived free radical in patients with diabetes. Circulating granulocytes and monocytes isolated from diabetic patients exhibit increased production of oxygen-derived free radicals $(52,53)$. Increased production of free radicals is also observed in normal granulocytes and monocytes exposed to hyperglycemia (54). Autoxidation of glucose catalyzed by transition metals and glycosylation of proteins can also generate excess oxygen-derived free radicals (55-57). Lastly, experimental hyperglycemia in animals increases AA metabolism and eicosanoid synthesis $(33,37,58,59)$. Enhanced eicosanoid synthesis results in increased production of oxygen-derived free radicals (60-62).

In our study, vitamin $\mathrm{C}$ restored $\sim 60 \%$ of the attenuated endothelium-dependent vasodilation observed in diabetic subjects compared with age-matched nondiabetic subjects. It is possible that administration of a higher dose of vitamin $\mathrm{C}$ could have scavenged more superoxide anion and resulted in a greater improvement in endothelium-dependent vasodilation in diabetic subjects. Alternatively, other factors may contribute to endothelial dysfunction in diabetic subjects. One potential mechanism leading to endothelial dysfunction in diabetes mellitus is the formation of advanced glycosylation end products (AGEs). Protein glycosylation and cross-linking reactions mediated by hyperglycemia results in the formation of AGEs which deposit in the subendothelial layer and induce vascular dysfunction. AGEs can directly inactivate endotheliumderived nitric oxide and cause impaired endothelium-dependent vasodilation (63). In normal animals, administration of exogenous AGEs resulted in increased AGE deposition in vascular tissue, increased vascular permeability, increased monocyte infiltration into the subendothelial layer, and impaired endothelium-dependent vasodilation (64). All these vascular abnormalities were prevented by concomitant administration of the protein cross-linking inhibitor aminoguanidine. Another pathway to account for endothelial dysfunction in diabetic subjects is the high levels of glycosylated hemoglobin. In vitro experiments that incubated isolated aortic rings from normal rats with glycosylated hemoglobin resulted in impaired endothelium-dependent relaxation (65). Finally, studies in vitro have shown that hyperglycemia enhances the oxidation of LDL $(66,67)$. Oxidized LDL may promote endothelial dysfunction by several mechanisms, such as damaging endothelial membrane receptors for vasodilator agonists, decreasing synthesis and release of endothelium-derived nitric oxide, and directly inactivating endothelium-derived nitric oxide (68-72).

In conclusion, acute administration of the antioxidant, vitamin $\mathrm{C}$, improved endothelium-dependent vasodilation in patients with non-insulin-dependent diabetes mellitus. This finding supports our hypothesis that oxygen-derived free radicals contribute to abnormal vascular reactivity in diabetes. Restoring endothelial function has important clinical implications for reducing the risk of vascular disease in diabetic patients. Future studies examining the long-term effects of oral antioxidant vitamin supplementation on vascular function and cardiovascular morbidity and mortality will be required before antioxidant vitamin supplementation can be recommended.

\section{Acknowledgments}

This research was supported by a National Institutes of Health Program Project Grant in Vascular Biology and Medicine (HL-48743). M. A. Creager is a recipient of a National Heart, Lung, and Blood Institute Academic Award in Systemic and Pulmonary Vascular Medicine (HL-02663).

\section{References}

1. Kannel, W. B., and D. L. McGee. 1979. Diabetes and cardiovascular disease. JAMA (J. Am. Med. Assoc.). 241:2035-2038.

2. Nathan, D. M. 1993. Long-term complications of diabetes mellitus. $N$. Engl. J. Med. 328:1676-1685.

3. Clark, C. M., and D. A. Lee. 1995. Prevention and treatment of the complications of diabetes mellitus. N. Engl. J. Med. 332:1210-1217.

4. Merimee, T. J. 1990. Diabetic retinopathy: a synthesis of perspectives. $N$. Engl. J. Med. 322:978-983.

5. Zatz, R., and B. M. Brenner. 1986. Pathogenesis of diabetic microangiopathy: the hemodynamic view. Am. J. Med. 30:443-453.

6. Furchgott, R. F., and J. V. Zawadzki. 1980. The obligatory role of endothelial cells in the relaxation of arterial smooth muscle by acetylcholine. Nature (Lond.). 288:373-376.

7. Palmer, R. M. J., D. S. Ashton, and S. Moncada. 1988. Vascular endothelial cells synthesize nitric oxide from L-arginine. Nature (Lond.). 333:664-666.

8. Vallance, P., J. Collier, and S. Moncada. 1989. Effects of endotheliumderived nitric oxide on peripheral arterial tone in man. Lancet. ii:997-1000.

9. Stamler, J. S., E. Loh, M. A. Roddy, K. E. Currie, and M. A. Creager. 1994. Nitric oxide regulates basal systemic and pulmonary vascular resistance in healthy humans. Circulation. 89:2035-2040.

10. Saenz de Tejada, I. S., I. Goldstein, K. Azadzoi, R. J. Krane, and R. A. Cohen. 1989. Impaired neurogenic and endothelium-mediated relaxation of penile smooth muscle from diabetic men with impotence. N. Engl. J. Med. 320: 1025-1030.

11. Calver, A. C., J. G. Collier, and P. J. T. Vallance. 1992. Inhibition and stimulation of nitric oxide synthesis in the human forearm arterial bed of patients with insulin-dependent diabetes. J. Clin. Invest. 90:2548-2554.

12. Johnstone, M. T., S. J. Creager, K. M. Scales, J. A. Cusco, B. K. Lee, and M. A. Creager. 1993. Impaired endothelium-dependent vasodilation in patients with insulin-dependent diabetes mellitus. Circulation. 88:2510-2516.

13. Elliot, T. G., J. R. Cockcroft, P. H. Groop, G. C. Viberti, and J. M. Ritter. 1993. Inhibition of nitric oxide synthesis in the forearm vasculature of insulin-dependent diabetic patients: blunted vasoconstriction in patients with microalbuminuria. Clin. Sci. (Lond.). 85:687-693. 
14. McVeigh, G. E., G. M. Brennan, G. D. Johnston, B. J. McDermott, L. T. McGrath, W. R. Henry, J. W. Andrews, and J. R. Hayes. 1992. Impaired endothelium-dependent and independent vasodilation in patients with type 2 (non-insulin-dependent) diabetes mellitus. Diabetologia. 35:771-776.

15. Williams, S. B., J. A. Cusco, M. A. Roddy, M. T. Johnstone, and M. A. Creager. 1994. Impaired nitric oxide-mediated vasodilation in non-insulindependent diabetes. J. Am. Coll. Cardiol. 1996. In press.

16. Tesfamariam, B., and R. A. Cohen. 1992. Free radicals mediate endothelial cell dysfunction caused by elevated glucose. Am. J. Physiol. 263:H321H326.

17. Bohlen, H. G., and J. M. Lash. 1993. Topical hyperglycemia rapidly suppresses EDRF-mediated vasodilation of normal rat arterioles. Am. J. Physiol. 265:H219-H225.

18. Diederich, D., J. Skopec, A. Diederich, and F. Dai. 1994. Endothelial dysfunction in mesenteric resistance arteries of diabetic rats: role of free radicals. Am. J. Physiol. 266:H1153-H1161.

19. Langenstroer, P., and G. M. Pieper. 1992. Regulation of spontaneous EDRF release in diabetic rat aorta by oxygen free radicals. Am. J. Physiol. 263: $\mathrm{H} 257-\mathrm{H} 265$.

20. Hattori, Y., H. Kawasaki, A. Kazuhiro, and M. Kanno. 1991. Superoxide dismutase recovers altered endothelium-dependent relaxation in diabetic rat aorta. Am. J. Physiol. 261:H1086-H1094.

21. Block, G., and M. Levine. 1991. Vitamin C: a new look. Ann. Intern. Med. 114:909-910.

22. Frei, B., R. Stocker, and B. N. Ames. 1988. Antioxidant defenses and lipid peroxidation in human blood plasma. Proc. Natl. Acad. Sci. USA. 85:97489752.

23. Frei, B., L. England, and B. N. Ames. 1989. Ascorbate is an outstanding antioxidant in human blood plasma. Proc. Natl. Acad. Sci. USA. 86:6377-6381.

24. Retsky, K. L., M. W. Freeman, and B. Frei. 1993. Ascorbic acid oxidation products protect human low density lipoprotein against atherogenic modification. J. Biol. Chem. 268:1304-1309.

25. Chen, M. S., M. L. Hutchinson, R. E. Pecoraro, W. Y. Lee, and R. F. Labbe. 1983. Hyperglycemia-induced intracellular depletion of ascorbic acid in human mononuclear leukocytes. Diabetes. 32:1078-1081.

26. Yue, D. K., S. McLennon, E. Fisher, S. Heffernan, C. Capogreco, G. R. Ross, and J. R. Turtle. 1989. Ascorbic acid status and polyol pathway in diabetes. Diabetes. 38:257-261.

27. Cunningham, J. J., S. L. Ellis, K. L. McVeigh, R. E. Levine, and J. Calles-Escandon. 1991. Reduced mononuclear leukocyte ascorbic acid content in adults with insulin-dependent diabetes mellitus consuming adequate dietary vitamin C. Metab. Clin. Exp. 40:146-149.

28. National Diabetes Data Group. 1979. Classification and diagnosis of diabetes mellitus and other categories of glucose intolerance. Diabetes. 28:10391057.

29. Pieper, G. M., and G. Gross. 1988. Oxygen-derived free radicals abolish endothelium-dependent relaxation in diabetic rat aorta. Am. J. Physiol. 255: H825-H833.

30. Meraji, S., L. Jayakody, P. J. Senaratne, A. B. R. Thomson, and T. Kappagoda. 1987. Endothelium-dependent relaxation in aorta of BB rat. Diabetes. 36:978-981.

31. Durante, W., A. K. Sen, and F. A. Sunahara. 1988. Impairment of endothelium-dependent relaxation in aortae from spontaneously diabetic rats. $\mathrm{Br}$. J. Pharmacol. 94:463-468.

32. Abiru, T., Y. Watanabe, K. Kamata, N. Miyata, and Y. Kasuya. 1990. Decrease in endothelium-dependent relaxation and levels of cyclic nucleotides in aorta from rabbits with alloxan-induced diabetes. Res. Commun. Chem. Pathol. Pharmacol. 68:13-25.

33. Tesfamariam, B., J. A. Jakubowski, and R. A. Cohen. 1989. Contraction of diabetic rabbit aorta caused by endothelium-derived PGH2-TxA2. Am. J. Physiol. 257:H1327-H1333.

34. Mayhan, W. G. 1989. Impairment of endothelium-dependent dilatation of cerebral arterioles during diabetes mellitus. Am. J. Physiol. 256:H621-H625.

35. Lash, J. M., and H. G. Bohlen. 1991. Structural and functional origins of suppressed acetylcholine vasodilation in diabetic rat intestinal arterioles. Circ. Res. 69:1259-1268.

36. Oyama, Y., H. Kawasaki, Y. Hattori, and M. Kanno. 1986. Attenuation of endothelium-dependent relaxation in aorta from diabetic rats. Eur. J. Pharmacol. 131:75-78.

37. Tesfamariam, B., M. L. Brown, D. Deykin, and R. A. Cohen. 1990. Elevated glucose promotes generation of endothelium-derived vasoconstrictor prostanoids in rabbit aorta. J. Clin. Invest. 85:929-932.

38. Gryglewski, R. J., R. M. J. Palmer, and S. Moncada. 1986. Superoxide anion is involved in the breakdown of endothelium-derived vascular relaxing factor. Nature (Lond.). 320:454-456.

39. Mugge, A., J. H. Elwell, T. E. Peterson, and D. G. Harrison. 1991. Release of intact endothelium-derived relaxing factor depends on endothelial superoxide dismutase activity. Am. J. Physiol. 260:C219-C225.

40. Rubanyi, G. M., and P. M. Vanhoutte. 1986. Oxygen-derived free radicals, endothelium, and responsiveness of vascular smooth muscle. Am. J. Physiol. 250:H815-H821.

41. Beckman, J. S., T. W. Beckman, J. Chen, P. A. Marshall, and B. A.
Freeman. 1990. Apparent hydroxyl radical production by peroxynitrite: implications for endothelial injury from nitric oxide and superoxide. Proc. Natl. Acad. Sci. USA. 87:1620-1624.

42. Minor, R. L., P. R. Myers, R. Guerra, J. N. Bates, and D. G. Harrison. 1990. Diet-induced atherosclerosis increases the release of nitrogen oxides from rabbit aorta. J. Clin. Invest. 86:2109-2116.

43. Mugge, A., J. H. Elwell, T. E. Peterson, T. G. Hofmeyer, D. D. Heistad, and D. G. Harrison. 1991. Chronic treatment with polyethylene-glycolated superoxide dismutase partially restores endothelium-dependent vascular relaxations in cholesterol-fed rabbits. Circ. Res. 69:1293-1300.

44. White, C. R., T. A. Brock, L. Y. Chang, J. Crapo, P. Briscoe, D. Ku, W. A. Bradley, S. H. Gianturco, J. Gore, B. A. Freeman, and M. M. Tarpey. 1994. Superoxide and peroxynitrite in atherosclerosis. Proc. Natl. Acad. Sci. USA. 91:1044-1048.

45. Ohara, Y., T. E. Peterson, H. S. Sayegh, R. R. Subramanian, J. N. Wilcox, and D. G. Harrison. 1995. Dietary correction of hypercholesterolemia in the rabbit normalizes endothelial superoxide anion production. Circulation. 92: 898-903.

46. Nishikimi, N. 1975. Oxidation of ascorbic acid with superoxide anion generated by the xanthine-xanthine oxidase system. Biochem. Biophys. Res. Commun 63:463-468.

47. Som, S., C. Raha, and I. B. Chatterjee. 1983. Ascorbic acid: a scavenger of superoxide radical. Acta Vitaminol. Enzymol. 5:243-250.

48. Gotoh, N., and E. Niki. 1992. Rates of interactions of superoxide with vitamin $\mathrm{E}$, vitamin $\mathrm{C}$, and related compounds as measured by chemiluminescence. Biochim. Biophys. Acta. 1115:201-207.

49. Tsujimoto, Y., H. Hashizume, and M. Yamazaki. 1993. Superoxide radical scavenging activity of phenolic compounds. Int. J. Biochem. 25:491-494

50. Huie, R. E., and S. Padmaja. 1993. The reaction of NO with superoxide. Free Radical Res. Commun. 18:195-199.

51. Theron, A., and R. Anderson. 1985. Investigation of the protective effects of the antioxidants ascorbate, cysteine, and dapsone on the phagocytemediated oxidative inactivation of human alpha-1-protease inhibitor in vitro. Am. Rev. Respir. Dis. 132:1049-1054.

52. Hiramatsu, K., and S. Arimori. 1988. Increased superoxide anion production by mononuclear cells of patients with hypertriglyceridemia and diabetes. Diabetes. 37:832-834.

53. Wierusz-Wysocka, B., H. Wysocki, A. Siekierka, A. Wykretowicz, A Szczepanik, and R. Klimas. 1987. Evidence of polymorphonuclear neutrophil activation in patients with insulin-dependent diabetes mellitus. J. Leukocyte Biol. 42:519-523.

54. Schroder, S., W. Palinski, and G. W. Schmid-Schonbein. 1991. Activated monocytes and granulocytes, capillary nonperfusion, and neovascularization in diabetic retinopathy. Am. J. Pathol. 139:81-100.

55. Wolff, S. P., and R. T. Dean. 1987. Glucose autoxidation and protein modification. The potential role of oxidative glycosylation in diabetes. Biochem. J. 245:243-250.

56. Hunt, J. V., C. C. T. Smith, and S. P. Wolff. 1990. Autoxidative glycosylation and possible involvement of peroxides and free radicals in LDL modification by glucose. Diabetes. 39:1420-1424.

57. Hunt, J. V., R. T. Dean, and S. P. Wolff. 1988. Hydroxyl radical produc tion and autoxidative glycosylation: glucose autoxidation as the cause of protein damage in the experimental glycation model of diabetes mellitus and ageing. Biochem. J. 256:205-212.

58. Brown, M. L., J. A. Jakubowski, L. L. Leventis, and D. Deykin. 1988. Elevated glucose alters eicosanoid release from porcine aortic endothelial cells. J. Clin. Invest. 82:2136-2141.

59. Wolf, B. A., J. R. Williamson, R. A. Easom, K. Chang, W. R. Sherman, and J. Turk. 1991. Diacylglycerol accumulation and microvascular abnormalities induced by elevated glucose levels. J. Clin. Invest. 87:31-38.

60. Kukreja, R. C., H. A. Kontos, M. Z. Hess, and E. F. Ellis. 1986. PGH synthase and lipoxygenase generate superoxide in the presence of NADH and NADPH. Circ. Res. 59:612-619.

61. Kontos, H. A. 1987. Oxygen radicals from arachidonate metabolism in abnormal vascular responses. Am. Rev. Respir. Dis. 136:474-477.

62. Sing, D. J., J. Greenwald, E. N. Metz, J. Bianchine, and A. L. Sagone. 1981. Evidence for the generation of hydroxyl radical during arachidonic acid metabolism by human platelets. Am. J. Hematol. 11:233-237.

63. Bucala, R., K. J. Tracey, and A. Cerami. 1991. Advanced glycosylation products quench nitric oxide and mediate defective endothelium-dependent vasodilation in experimental diabetes. J. Clin. Invest. 87:432-438.

64. Vlassara, H., H. Fuh, Z. Makita, S. Krungkrai, A. Cerami, and R. Bucala. 1992. Exogenous advanced glycosylation end products induce complex vascular dysfunction in normal animals: a model for diabetic and ageing complication. Proc. Natl. Acad. Sci. USA. 89:12043-12047.

65. Rodriguez-Manas, L., S. Arribas, C. Giron, J. Villamor, C. F. SanchezFerrer, and J. Marin. 1993. Interference of glycosylated human hemoglobin with endothelium-dependent responses. Circulation. 88:2111-2116.

66. Kawamura, M., J. W. Heinecke, and A. Chait. 1994. Pathophysiological concentrations of glucose promote oxidative modification of low density lipoprotein by a superoxide-dependent pathway. J. Clin. Invest. 94:771-778.

67. Heinecke, J. W., L. Baker, H. Rosen, and A. Chait. 1986. Superoxide- 
mediated modification of low density lipoprotein by arterial smooth muscle cells. J. Clin. Invest. 77:757-761.

68. Witztum, J. L., and D. Steinberg. 1991. Role of oxidized low density lipoprotein in atherogenesis. J. Clin. Invest. 88:1785-1792.

69. Kugiyama, K., S. A. Kerns, J. D. Morrisett, R. Roberts, and P. D. Henry. 1990. Impairment of endothelium-dependent arterial relaxation by lysolecithin in modified low density lipoproteins. Nature (Lond.). 344:160-162.

70. Flavahan, N. A. 1993. Lysophosphatidylcholine modifies G protein- dependent signaling in porcine endothelial cells. Am. J. Physiol. 264:H722H727.

71. Flavahan, N. A. 1992. Atherosclerosis or lipoprotein-induced endothelial dysfunction: potential mechanisms underlying reduction in EDRF/nitric oxide activity. Circulation. 85:1927-1938.

72. Galle, J., A. Mulsch, R. Busse, and E. Bassenge. 1991. Effects of native and oxidized low density lipoproteins on formation and inactivation of endothelium-derived relaxing factor. Arterioscler. Thromb. 11:198-203. 